\section{THE TREATMENT OF CARCINOMA OF THE CERVIX WITH RADIUM.}

BY

GILBERT I. STRACHAN; M.D., M.R.C.P., F.R.C.S.,

ASSISTANT OBSTETRICIAN AND GYNAECOLOGIST, CARDIFF ROYAL INTIRMARY; FIRST ASSISTANT TO PROFESSOR OF OBSTETRICS AND GYNAECOLOGY, WELSH MATIONAL SCHOOL OF MEDICINE.

ThE wide prevalence and extreme malignancy of carcinoma of the cervix are well appreciated by all practitioners, and any method of treatment which promises cure or alleviation calls for careful investigation.

In operable cases the results of surgical excision, especially in expert hands, have been of great benefit, and many lives have been saved by this method. But it is common experience that in many cases presenting themselves for the first time for examination the disease is advanced beyond the possibility of operative removal. This "operability rate" is estimated with considerable variations in different centres and according to the personal leanings of different surgeons. Bonney finds only $36 \mathrm{per}$ cent. of his cases inoperable, while in the Cancer Hospital, London (Cole), the percentage is quoted at from 88 to 93, and other centres quote intermediate figures. Taking involvement of the adjacent vaginal wall as a useful criterion of inoperability, we find in Cardiff that 90 per cerrt. of our cases of carcinoma of the cervix are inoperable when first seen. For the alleviation of these advanced cases many palliative remedies have been advocated, and the most important of these is exposure to the gamma rays of radium. It is our experience with this method of treatment in advanced cases of carcinoma of the cervix that we wish to discuss in this paper.

\section{The Action of Radium.}

It would be out of place in this article to discuss the physics of radium, but the clinical effect on tissues can be colsidered. In general terms the action of radium is to produce cellular death, but this effect varies within wide limits with the amount of radium used, the duration of exposure, and the type of tissue involved. The destructive effect is most marked in the case of embryonic cells, as in a malignant growth, or in the Graafian follicles of the ovary; it is less marked in the more mature cells of a benign neoplasm, and is least marked in the case of the adult trpe of cells forming the parenchyma of organs.

The important point now emerges that the more malignant a tumour the more susceptible is it to the destructive action of radium (Bergonié and Tribondeau), and several workers, such as Ewing, Martzloff, Broders, and others, have attempted to judge from the degree of malignancy or anaplasia of the cells of tumours the degree of radioresistance or radio-sensitiveness of these tumours, and the corresponding likelihood of radium being effective as a remedial agent or the reverse. These researches have not been of great practical value, and at present we know of no criteria by which the effect of radium on a given carcinoma can be foretold.

The exact manner in which radium produces its lethal effect is not yet known. It may be by a direct action on the tumour cells, or by an indirect action, such as by the production of thrombosis or of antibodies. Ewing is of opinion that the constituents of the cells are ionized and the intercellular ferments stimulated, while Dixon points out that radium has a marked effect in decomposing lecithin; and it is just those tissues which are rich in lecithin which are most affected by radium. The cellular degeneration may therefore be due to the effects of the decomposed lecithin. The known action of radium in producing thrombosis must also be kept in mind as at least a contributory factor in this respect.

The clinical changes occurring in a carcinoma of the cervix reacting satisfactorily to radium have lately been summarized by Farrar of New York as (1) hyperaemia one week after the application; (2) slough formation on the surface of the cervix three weeks later; (3) separation of the slough one month later; (4) a stage of contraction due to fibrosis after another month; and (5) a final stage of marked upper vaginal and cervical contraction. These findings are in general accord with our own experience, but the time factors have been found to be somewhat more variable than those stated. The histological changes occurring as the result of irradiation have been described by several writers, and need not be gone into here.

\section{Preliminary Examination.}

While irradiation is the treatment of election in advanced cases of carcinoma of the cervix, not every case in this category is suitable for radium, and for this reason alone it is necessary to carry out a careful preliminary investigation in every case which it is proposed to treat by this agent. The following points call for investigation.

1. The general condition of the patient is important. A cachectic and emaciated patient is a poor subject for radium, which in such a case may do more harm than good. In these cases radium should be withheld until the general condition has improved, if it is going to improve, by rest and appropriate feeding.

2. Anaemia from repeated haemorrhages or from toxic absorption from a foul cervix should be looked for in every case. In general it can be laid down that, with a red cell count of 3 million or under, or with a haenoglobin index below 40, radium should not be applied on account of the danger of still further increasing the anaemia.

3. Extensions of the disease should be investigated. Tenderness and swelling in the loins would indicate hydroor pyo-nephrosis from ureteral obstruction, and would constitute a contraindication to irradiation. Increased liver dullness, especially if associated with jaundice, points to secondaries in this organ, while suprapubic swelling might point to pyometra.

4. The local condition is to be carefully examined, if necessary under anaesthesia, and the size, character, and extent of the tumour accurately estimated, as well as the degree of parametrial infiltration and uterine fixation present. The size of the uterus is important: if enlarged it may indicate pyometra, and in such a case careful uterine exploration should be carried out. The fornices should be carefully palpated for any signs of salpingitis, pyosalpinx, or pelvic abscess. It has to be emphasized that in the presence of any inflammatory pclvic lesion, such as a foul carcinomatous ulcer, pyometra, pyosalpinx, or pelvic abscess, radium should not be applied until the condition is cleared up, owing to the risk of setting up peritonitis.

5. Involvement of rectum or bladder, as indicated by symptoms of tenesmus, dysuria, or bleeding, or as found on physical examination, would constitute contraindications to irradiation. The disease is far advanced in such cases, and the effect of radium would be merely to hasten fistula formation. It follows that the presence of a definite fistula into either of these organs, especially into the bladder, would render the case unsuitable for radium. Occasionally radium may be applied in the presence of a small rectal fistula, but never in the presence of a vesical fistula.

Only after a thorough preliminary examination of this nature should radium be applied.

Techeique of Application.

In different clinics in this country, on the Continent, and in America considerable variations exist regarding the amount of radium to be applied, the duration of dosage, and the manner of insertion. The technique here described has been evolved by us since 1922 .

Before radiation the vagina is douched twice daily with weak lysol, and the rectum cleared as for perineorrhaphy. If the surface of the carcinoma be foul, radiation is postponed and douching continued until it is clean.

With the patient under anaesthesia in the lithotomy position, a final bimanual examiuation is made to verify the points mentioned above, and after exposure with a speculum the cervix and vagina are thoroughly swabbed with tincture of iodine. If possible, the cervix is now gently steadied by vulsella, but in advanced cases there may be no cervix left owing to extensive ulceration. A section of the tumour, if possible with a piece of the adjacent healthy tissue, is now taken for microscopical examination.

A sound is then passed through the cervical canal in order to determine the position of this in the ulcer, to estimate the size of the uterine cavity, and to explore for the presence or absence 
of pyometra. If pyometra be present the cervix is dilated and the condition drained, while radiation is postponed until the uterine discharge has ceased. It may be very difficult, and in some cases impossible, to find the cervical canal in the midst of the carcinoma, but prolonged and gentle attempls should be made for the reasons stated; in such difficult cases the canal is often to be found at some point in the periphery of the growth. One 50-mg. tube of radium sheathed in platinum is then introduced with Pinch's forceps well up the cervical canal; if the growth extends particularly to one or other side a tube of $25 \mathrm{mg}$. is inserted in this extension, while round about the periphery of the turnour five or six 10-mg. tubes are buried. The 50 and $25 \mathrm{mg}$. tubes are $2.5 \mathrm{~cm}$. in length, and the $10-\mathrm{mg}$. tubes are $1.7 \mathrm{~cm}$. in length. They are of platinum, and one end is pointed, while at the opposite cxtremity is an eye through which a length of silk is threaded. These radium tubes should be inserted well up into the substance of the growth.

The silk threads from the eyes of the radium tubes are then knotted together, and this strand is tied to the end cf a roll of gauze, which is firmly packed into the vagina, especially into the anterior and posterior fornices, so as to keep the rectum and bladder as far from the effects of the radium as possible. Finally, $a$ self-retaining catheter is passed into the bladder.

After twenty-four hours the catheter and packing are taken out, and along with the latter the radium tubes arc easily removed by gentle traction. Another vaginal douche of lysol is given.

The amount of radium inserted therefore depends to some degree on the extent of the lesion, and in this respect we fully agree with Ward of New York, who maintains that every case is an individual study, and that no definite dosage can be laid down for all cases. The usual dosage is from 125 to $150 \mathrm{mg}$., and this, left in for twenty-four hours, represents a milligram-hour dosage of from 3,000 to 3,600 .

Daily douches are given, and the patient is allowed up in a few days, and usually goes home by the end of the week. She is instructed to give herself a daily vaginal douche until she reports again for examination in four weeks' time. This is beneficial not only in keeping the parts clean but also in the prevention of raginal stenosis. The patient is examined again in a month and after that at intervals. Further irradiation depends entirely on the reaction of the tumour to the first insertion. In some cases it has been found that a single irradiation produces a beneficial and evidently permanent effect, while in other cases sereral applications have been required.

Deep $x$-ray therapy, applied either to or subsequent to local radiation, is now being used in a number of clinics. While it is difficult to find any figures to show improved results from this therapy, it is likely that in the future this will form an important adjunct to local radiation, especially with improved technique of application. The main objection to deep $x$-ray therapy has been that the action is not localized to diseased tissues, and that healthy organs, such as the bowel, may be affected, with resulting gangrene and perforation. These accidents have happened, but with more modern and improved technique it is likely that this aspect will be eliminated and the rays concentrated more especially on the diseased parts.

\section{Clinical Results.}

In considering these it will be seen that the majority of patients with carcinoma of the cervix treated by radium have died at varying intervals. But in this connexion it has to be remembered that all these cases were advanced when first seen, with involvement of the raginal walls, and mostly with impaired uterine mobility and parametrial infiltration. They were inoperable by any usual clinical standard, and under these circumstances a high mortality is to be expected. It has to be emphasized that no patient died as the result of irradiation.

In discussing results it is unsafe to use the word " cure," as experience has shown that a number of cases apparently cured recurred even after several years, and it is better to use such terms as "alive" or "free of symptoms". in describing such cases.

Since we started using radium in this condition, late in 1922, 153 cases have been treated, and of these 40 are now alive, while 113 are known to be dead or have failed to report. It may be stated in passing that, as the result of the help which we obtain from the Cardiff, Glamorganshire, and Monmouthshire health authorities, no case has been lost sight of for the last three years, and we acknowledge our deep gratitude to these bodies. The cases (40) still alive may be tabulated as follows:

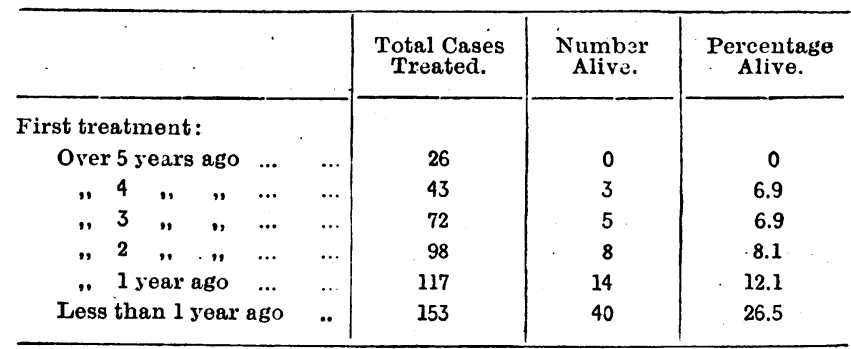

Of the other 113 cases, 89 are known to have died, while 24 have been lost sight of. While it is certain that at least the majority in this category of "failed to report" have died, they cannot be included for statistical purposes. These 89. cases can be tabulated in this way:

$$
\begin{aligned}
& \text { Duration of Life since First } \\
& \text { Irradiation. } \\
& \text { Over } 5 \text { years ... } \\
& \text { " } 4 \text { " } \\
& \text { ", } 3 \text { " } \\
& \text { " } 18 \text { months } \\
& \text { ", } 12 \text {," } \\
& \text { ", } 6 \\
& \text { Under } 6 \text { months } \\
& \begin{array}{ll} 
& \\
\ldots & \\
\ldots & \cdots \\
\ldots & \cdots \\
\ldots & \cdots \\
\ldots & \cdots \\
\ldots & \cdots \\
\ldots & \cdots
\end{array}
\end{aligned}
$$

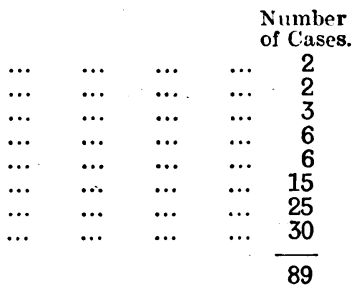

The average duration of life in these patients who died was 13.2 months.

Practically all the deaths occurred after discharge from hospital, so that in rery few cases were post-mortem examinations obtainable. The reported cause of death was usually increasing weakness from toxic absorption or ascending renal infection (especially in cases where vesicovaginal fistulae had developed). Rarer causes were intestinal obstruction (2), pyaemia, and secondary anaemia and general exhaustion following the development of a large abscess in the buttock (1 each).

\section{Relief of Symptoms.}

Apart from the saving of life, an important feature in the successful use of radium is the amount of relief obtained from the distressing symptoms of uterine haemorrhage, foul discharge, and pelvic pain, and it is our opinion that even if life were not prolonged by a day irradiation would be justified in its use for this reason.

Haemorrhage was controlled in 90 per cent. of the cases; in 10 per cent. it recurred before death; and in 80 per cent. it ceased permanently. Vaginal discharge ceased in 60 por cent. of cases, and was improved in another 15 per cent. Pelvic pain was relieved in 45 per cent. of cases; in 30 per cent. it was not influenced; and in 25 per cent. it was aggravated or appeared for the first time after irradiation.

\section{Conclusrons.}

It is obvious from the foregoing that, while radium cannot as yet be described as a certain and definite " cure" in all cases of carcinoma of the cervix, the results are encouraging, taking into consideration the initial extent of the disease in the cases reported. It has to be remembered that this treatment is in its early stages, and with inproved technique, especially as regards the subjecting of all the primary and secondary tumour cells to the immodiate effects of radium, improved figures are confidently to be expected. There is a vast field here for investigation and research, which is being energetically carried out in many centres. As a palliative agent; however, radium is the most potent that we possess, and in this way alone it has abundantly justified its use in the relief of the distressing symptoms of the condition.

I feel compelled, in conclusion, to protest against the manner in which radium has been hailed as a "cure for cancer" by certain sections of the lay press. Much false hope and subsequent disappointment have been created by this propaganda, and although funds have in some cases 
been obtained for hospitals for the purchase of radium by these means, scientific and clinical progress has been correspondingly embarrassed.

The main hope of advance in the treatment of carcinoma by radium lies in the combined investigations of the clinician, the pathologist, and the phrsicist, and it is in this way only, and not by startling newspaper headlines, that future clinical results are likely to improve.

LITER:TLRE.

Bergonié, Tribondean, and Récamier: C. R. Soc. de Biolongin, 1905, 284. Broders: Journ. A mier Med Assoc, 1920.

Cole, Percival P. : British Medical Journal, 1925, ii, 831.

Dixon, W. E. : Ibid., 1929, i, 238

Farrar, Lilian K. P.: Surg., Gynecol, and Obstet., December, 1926, 719. Martzloff : Bull Johns Hoplins Ilosp, 1923, xxxiv, 141.

Ward, George Gray : British Medical Journal, 1928, ii, 607.

\section{TECHNIQUE OF INTRA-ABDOMINAL INSERTION OF RADIUM. FOR CARCINOMA OF THE CERVIX UTERI.}

\author{
BY
}

MALCOLM DONALDSON, M.B., F.R.C.S.,

Physician accoucheUr With the charge of OUt-patients, ST. BARTHOLOMEW'S HOSPITAL.

Ir will be many years before the public is sufficiently educated in medical matters to realize that periodic overhauls of their bodies are as necessary as for their motor car's. For a long time, therefore, there will be a large number of patients with advanced cancer, especially carcinoma of the cervix.

In discussing the problem of cancer treatment it is of some importance to consider why an advanced case of malignant disease should be more difficult to cure by radiotherapy than an early case. When dealing with "excisional surgery" it is easy to realize that if the diseased area is extensive it will be impossible with a knife to cut this out without excising portions of essential organs, with fatal results to the patient. In radiotherapy, on the other hand, it is not so easy to be certain why there is such difficulty in destroying malignant cells placed deep in the pelvis when it is so easy to destroy them if placed on the tip of the cervix. There are several possible explanations for this difference.

First, it may be the better blood supply that is found in the region of the deeper part of the growth: Strangeways and Fell found that the reaction of tissues in the embryonic chick to $x$ rays differed considerably before and after circulation had been established.

Secondly, it is possible that the cancer resistance of the body materially helps the radiotherapy in early cases, but that in the more advanced cases no such help is forthcoming. This idea is very seriously considered in Sweden.

Thirdly, the type of cell developed in these late cases may in itself be more radio-resistant; this, however, is hardly likely, as the cells in the cervix and more exposed part of the growth are just as easily destroyed in the late stages as in the early cases.

Fourthly, there is the simple explanation that it is more difficult to apply an efficient dose to these more distant cells. It is with this simple explanation in view that I am at the present time treating a series of patients by means of intra-abdominal radium.

It is to the Brussels Radium Institute that we owe the first attempt along these lines. The technique they used in 1919 consisted in putting the patient in the Trendelenburg position, opening the abdomen, and, when the posterior layer of the broad ligaments had been incised, placing $20 \mathrm{mg}$. of radium element in a single tube at the base of each ligament. In addition to this they sometimes put needles into the uterus. The sutures from these tubes were carried out through the lower end of the abdominal incision, and the whole pelvis was packed with 6 to 8 yards of gauze. At the end of four or five days this was removed, with or without an anaesthetic. I modified this technique by using needles instead of tubes. Thirteen cases were treated with a modified technique during 1923-24. Of these thirteen cases:

One was of the first degree and is living and well after four years.

Four were of the second degree, and of the four cases two are living after five years, although the latest report from one is not very satisfactory. Two have died, one after fourteen months and the other after seven months.

Six wore of the third degree; three of these six are living after five years or more, and three have died, having lived less than one year.

Two were of the fourth degree; one is living after five years and the other died after a year and ten months.

It will be seen, therefore, that of the thirteen cases six are alive after five years, and one has lived for four years and show's no signs of the disease.

\section{Present Technique.}

The intra-ahdominal insertion of radium is usually carried out about six to eight weeks after the vaginal application--that is to say, when the local external growth has disappeared and all ulceration healed. No attempt so far has been made to combine the intra-abdominal application at the same time as the vaginal, merely on the theoretical grounds that, whilst there is an infected area in the cervix and fornices, it is perhaps not wise to do anything to the abdomen and parametrium which might lower the resistance to that infection.

The patient is put into the Trendelenburg position and the abdomen opened, a general examination! is made of the liver and aortic glands, in addition to the pelvic organs and the iliac glands. The intestines are packed off and the uterus is pulled forward; the parietal peritoneum is then picked up with forceps and the needle inserted, leaving only the eye of the needle protruding from the peritoncum. The suture is put through a small portion of tho peritoneum below the level of the needle eye, and the knot tied over a glass bead to prevent cutting through the thin peritoneal tissue.

The needles are placed at a distance of 1 to $1 \frac{1}{2} \mathrm{~cm}$. from each other, starting at one sacro-iliac synchondrosis and ending at the corresponding joint of the opposite side. In addition four, or possibly more, needles are placed in front of the broad ligaments in the hope of eradicating tho disease from the obturator glands. The ends of the ligatures are tied together and pushed down into the pouch of Douglas. The abdomen is sewn up completely and the radium left in situ for seren days. At the end of this time the abdomen is again opened and the radium removed.

An objection to this technique is the second laparotomy at the end of a week, but up to the present it has been felt that in order to keep them in position the needles should be sutured to the peritoneum, which makes it impossible to pull them out. In addition to this they are often placed at an angle to the line of traction, and damage might be done if pulled out blindly. Dodd of the Westninster Hospital has modified this technique by using radium needles in catheters placed retro-peritoneally so that they can be withdrawn through stab incisions. In addition he combines this with excision of the glands.

\section{Immediate Results.}

The first case chosen in this series was a patient (second degree) in whom it was considered there was a reasonable chance of the treatment being of some value, and the operation took place in October, 1927 . Three or four months were allowed to elapse in order to see if there were any untoward symptoms before attempting the technique again. At the end of this time the patient was found to be extremely fit. During the year 1928 twelve other cases were treated in a similar manner. Of these, three were diagnosed as being first degree, two were of the second degree, two of the third degree, and five were of the fourth degree.

Of the first degree patients there is little to be said except that on opening the abdomen one of these was found to have enlarged obturator glands. The operation was done in September, 1928, but in December a letter stated that she did not feel very fit, and she died in February, 1929. Another, operated on in June, is very. 